\title{
Surface Hardening of Titanium by Using a Simplified Carbon and Nitrogen Diffusion Technique with Steel and Carbon Powders
}

\author{
Yasuhiro Morizono $^{1, * 1}$, Yuka Kawano ${ }^{1, * 2}$, Sadahiro Tsurekawa ${ }^{1}$ and Takateru Yamamuro ${ }^{2}$ \\ ${ }^{1}$ Department of Materials Science and Engineering, Graduate School of Science and Technology, Kumamoto University, \\ Kumamoto 860-8555, Japan \\ ${ }^{2}$ Technical Division, Faculty of Engineering, Kumamoto University, Kumamoto 860-8555, Japan
}

\begin{abstract}
Commercially pure titanium plates were embedded in mixtures of steel and activated carbon powders and then heated at $1273 \mathrm{~K}$ for $3.6 \mathrm{ks}$ in a nitrogen flow. During this simplified treatment, a Ti(C, N) layer with a thickness of approximately $10 \mu \mathrm{m}$ formed on the titanium surface. The surface hardness of the titanium plates coated with the Ti $(\mathrm{C}, \mathrm{N})$ layer was more than $\mathrm{HV}=1000$ regardless of the steel powder ratio in the mixture. Although a $\operatorname{Ti}(\mathrm{C}, \mathrm{N})$ layer formed upon heat treatment with the activated carbon powder alone, addition of the steel powder led to an increase in the surface hardness and layer thickness. From X-ray diffraction results, $\operatorname{Ti}(\mathrm{C}, \mathrm{N})$ began to form on the titanium plate heat-treated at $1073 \mathrm{~K}$ and became a complete layer at higher heating temperatures. Instead of activated carbon, the use of graphite with added alumina as a reliable anti-sintering agent had no negative effects on the formation of the $\mathrm{Ti}(\mathrm{C}, \mathrm{N})$ layer. [doi:10.2320/matertrans.M2012409]
\end{abstract}

(Received December 12, 2012; Accepted May 7, 2013; Published June 21, 2013)

Keywords: titanium, steel powder, activated carbon, graphite, alumina, pack cementation, Ti(C, N)

\section{Introduction}

Titanium and its alloys are used for applications in the automobile, aerospace and chemical industries because they have excellent corrosion resistances and high specific strengths. In addition, they can be used as biomaterials due to their good biocompatibilities. However, the major disadvantage with these materials is poor wear resistance. Since mechanical components and orthopedic implants with excellent tribological properties are required for practical use, techniques to harden the surface of titanium and its alloys have attracted great interest. Surface modification has been carried out by using various methods, such as gas nitriding, ${ }^{1)}$ plasma nitriding, ${ }^{2,3)}$ plasma carburizing, ${ }^{4)}$ and laser melting. ${ }^{2)}$ These methods need special equipment and complicated process flows to produce $\mathrm{TiC}$ and $\mathrm{TiN}$ layers on the base metal. Therefore, a simpler and quicker method is still desired.

The authors have previously investigated the interfacial microstructures and the bonding characteristics of titanium/ steel and Ti-Al alloy/steel joints produced by explosive welding and diffusion bonding. ${ }^{5-7)}$ As part of these experiments, interfacial reactions between steel powder and titanium material were examined to consider the possibility of surface modification via pack cementation. As a result, we developed a simplified treatment for the diffusion of carbon and nitrogen into titanium. Specifically, a titanium plate is embedded in a mixture of steel and activated carbon powders and is heated at $1273 \mathrm{~K}$ for $3.6 \mathrm{ks}$ in a nitrogen flow. During heating, a hardened layer, which has been identified as $\mathrm{Ti}(\mathrm{C}, \mathrm{N})$, forms on the titanium surface. Matsuura et al. have proposed a method of forming a $\operatorname{Ti}(\mathrm{C}, \mathrm{N})$ layer on a titanium surface. ${ }^{8)}$ In this method, a titanium specimen is heated in the temperature range of $1388-1573 \mathrm{~K}$ in a graphite cup under a nitrogen atmosphere. In contrast, our method uses steel

\footnotetext{
${ }^{* 1}$ Corresponding author, E-mail: morizono@gpo.kumamoto-u.ac.jp

${ }^{* 2}$ Graduate Student, Kumamoto University. Present address: Toyo Kohan Co., Ltd., Kudamatsu 744-8611, Japan
}

powder and has the great advantage of using a lower heating temperature. Moreover, heat treatment using a mixture of steel and carbon (activated carbon and graphite) powders enables carburization of stainless steel which is covered with a passive film of chromium oxide. ${ }^{9)}$ Although such powder pack methods may not be industrially suitable, they are noteworthy because they allow carbon and nitrogen to be easily diffused into metal substrates.

In the present study, a new treatment for the diffusion of carbon and nitrogen using steel and carbon powders applied to titanium is described, and its effectiveness is discussed on the basis of the microstructures and the hardness in the vicinity of the titanium surface.

\section{Experimental Procedure}

A commercially pure titanium plate with a purity of 99.5 mass \% was used as a substrate. The plate, which had a thickness of $1 \mathrm{~mm}$, was cut into square shapes with dimensions of $10 \mathrm{~mm} \times 10 \mathrm{~mm}$, and the surface was finished with \#1200 emery paper. The plates were then degreased in acetone using an ultrasonic cleaner and dried with hot air.

Mixtures of commercially available steel (carbonyl iron: $0.8-0.9$ mass $\% \mathrm{C}, \quad 0.7-0.9$ mass $\% \mathrm{~N}, \quad 0.2-0.4$ mass $\% \mathrm{O}$ ) and activated carbon powders were put into an alumina crucible, and the titanium plates were embedded in the mixtures. As shown in Fig. 1(a), the steel powder was fine and spherical. Figure 1(b) shows a scanning electron microscopic (SEM) image of the activated carbon powder. This was used as a carbon source and an anti-sintering agent. The volume ratio of the steel powder to the activated carbon powder was varied from $0: 100$ to $70: 30$. A further increase in the steel powder content made it difficult to take the specimen out of the powder mixture due to sintering. For comparison, graphite, which is shown in Fig. 1(c), was used instead of activated carbon. In some cases, alumina powder, shown in Fig. 1(d), was added to reliably prevent the powder mixture from sintering. The crucible packed with the titanium plate and the 

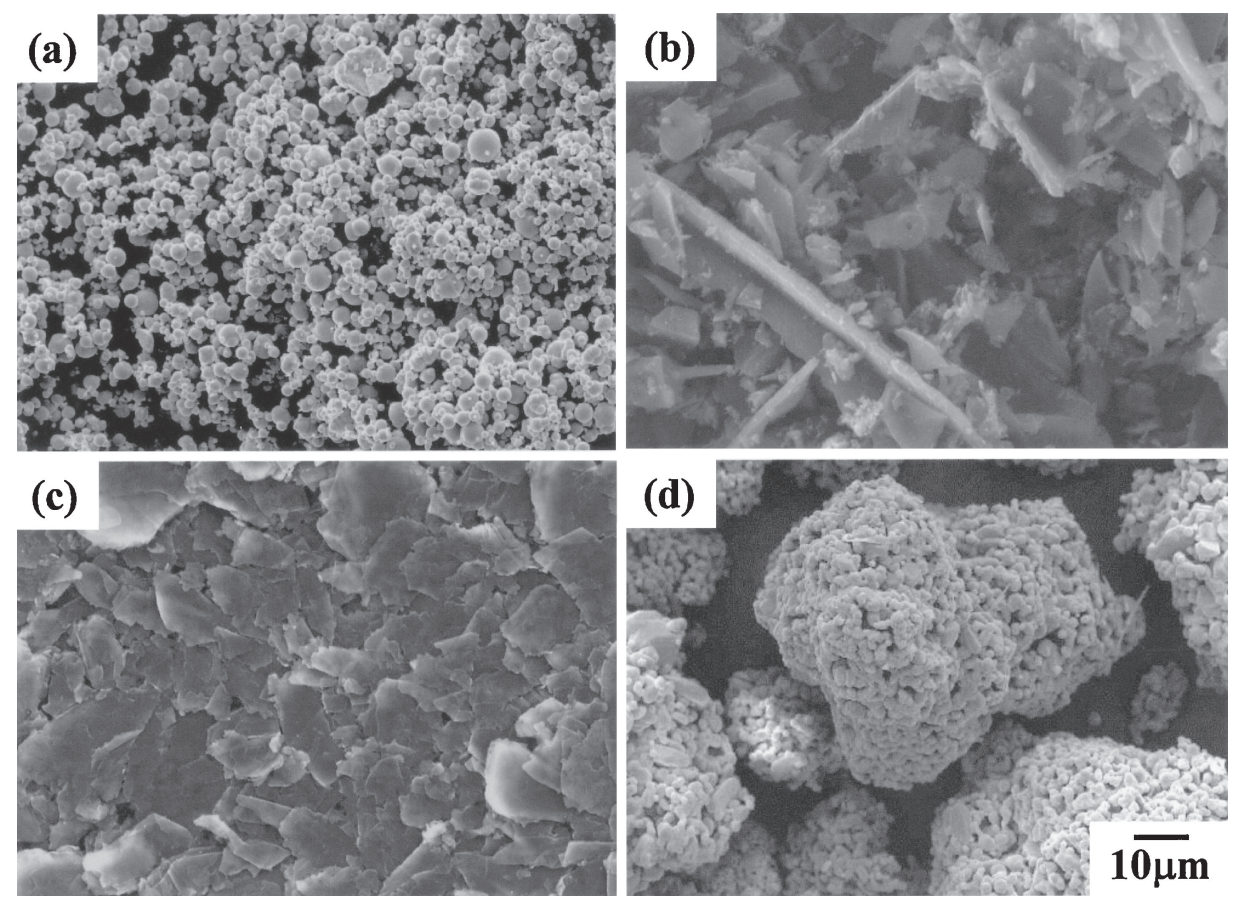

Fig. 1 SEM micrographs of (a) steel powder, (b) activated carbon powder, (c) graphite powder and (d) alumina powder.

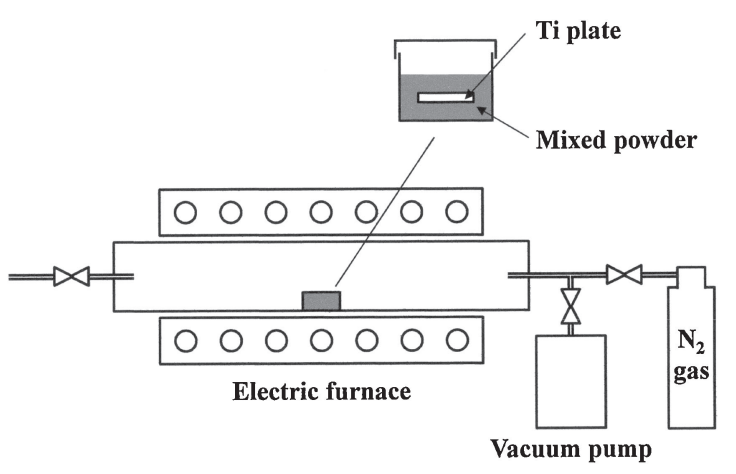

Fig. 2 Schematic illustration of the apparatus for carbon and nitrogen diffusion treatment.

powder mixture was placed in an electric furnace, as shown in Fig. 2. After repeatedly evacuating the furnace using a rotary vacuum pump and refilling it with nitrogen gas a few times, the crucible was heated in the temperature range of $773-1373 \mathrm{~K}$ for $3.6 \mathrm{ks}$ in a nitrogen flow. The gas had a purity of $>99.99 \mathrm{vol} \%$, and its flow rate was $500 \mathrm{ml} / \mathrm{min}$. All specimens were allowed to cool in the furnace to room temperature. In addition, a specimen heat-treated without the powder was prepared for comparison.

After heat treatment, X-ray diffraction (XRD) measurements, Vickers hardness tests and SEM observation were carried out on the titanium surfaces. In the hardness tests, a load of $0.49 \mathrm{~N}$ was applied at room temperature for $15 \mathrm{~s}$. Thereafter, the specimens were cut in half to reveal the microstructures. The cross sections were ground with emery paper and then mirror-finished using diamond slurry with a particle size of $0.5 \mu \mathrm{m}$. They were examined by using optical microscopy, SEM in conjunction with energy dispersive $\mathrm{X}$-ray spectroscopy (EDX), and electron probe X-ray micro analysis (EPMA). Before optical microscopy and SEM, the specimens were etched in an aqueous solution containing

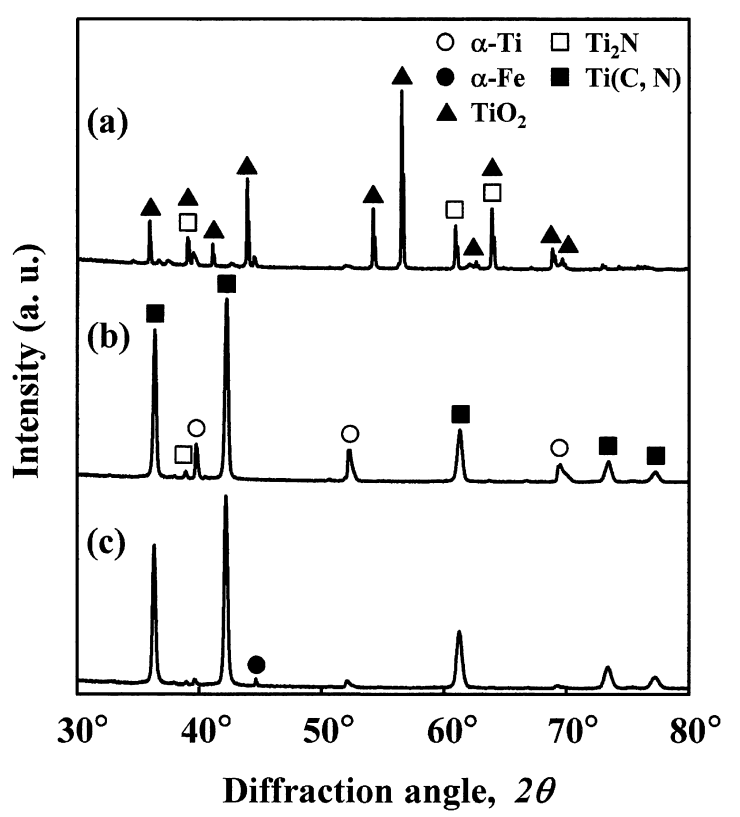

Fig. $3 \mathrm{XRD}$ patterns of the surface of a titanium plate heat-treated at $1273 \mathrm{~K}$ for $3.6 \mathrm{ks}$ in a nitrogen flow using various powders: (a) without powder, (b) activated carbon powder and (c) $10: 90(\mathrm{v} / \mathrm{v})$ mixture of steel and activated carbon powders.

hydrofluoric acid and nitric acid $\left(\mathrm{HF}: \mathrm{HNO}_{3}: \mathrm{H}_{2} \mathrm{O}=5: 25\right.$ : $70 \mathrm{v} / \mathrm{v} / \mathrm{v})$.

\section{Results and Discussion}

\subsection{Effects of a mixture of steel and activated carbon powders}

Figure 3(a) shows an XRD pattern of a titanium plate alone after heat treatment at $1273 \mathrm{~K}$ for $3.6 \mathrm{ks}$ in a nitrogen flow. The main reaction products were $\mathrm{TiO}_{2}$ and $\mathrm{Ti}_{2} \mathrm{~N}$. The formation of $\mathrm{TiO}_{2}$ suggests the presence of a small amount of 

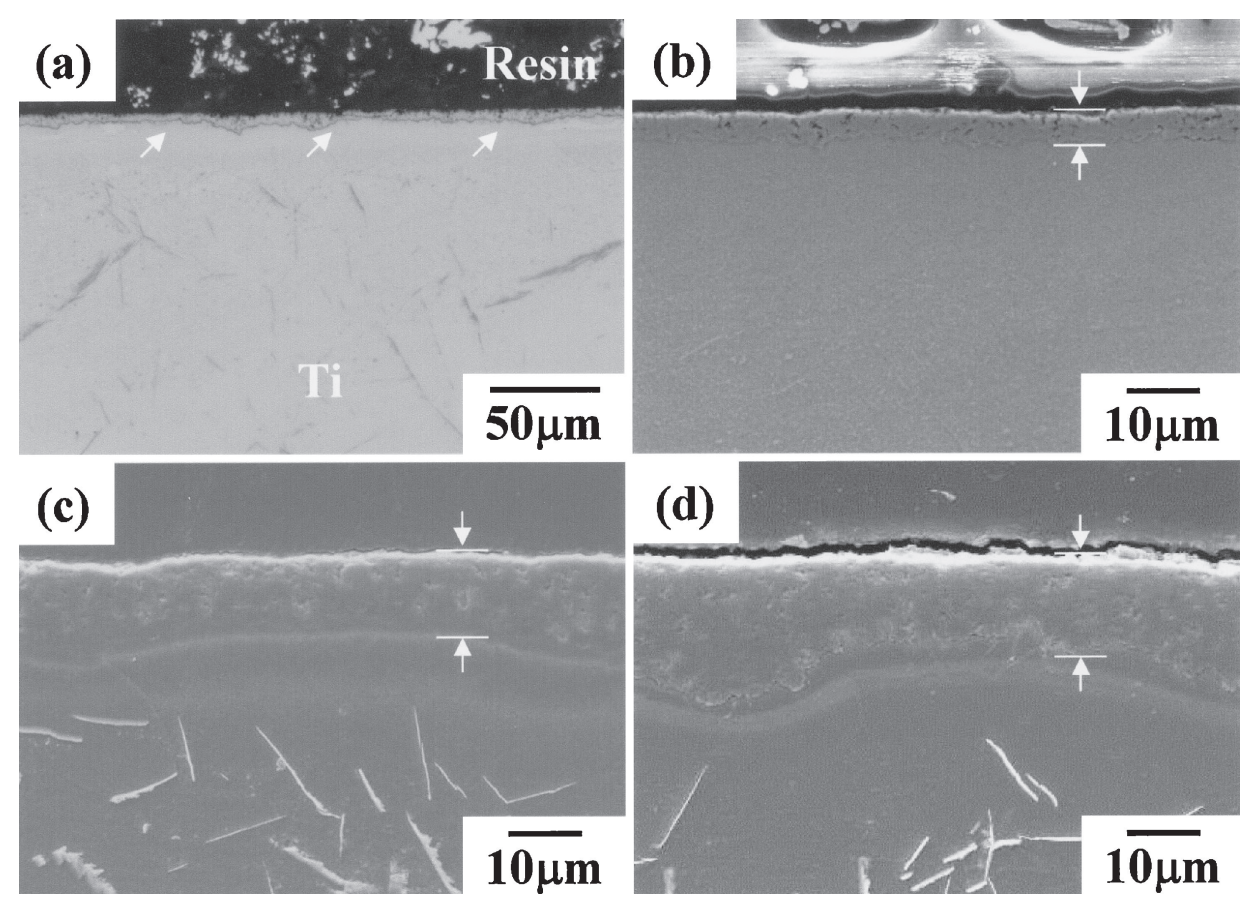

Fig. 4 (a) Optical and (b)-(d) SEM micrographs of cross section of a titanium plate heat-treated at $1273 \mathrm{~K}$ for $3.6 \mathrm{ks}$ in a nitrogen flow using various powder mixtures. The powder mixtures were composed of steel and activated carbon powders. Steel powder ratio in mixture: (a) and (b) 0 vol\%, (c) $10 \mathrm{vol} \%$ and (d) $40 \mathrm{vol} \%$.

oxygen in the atmosphere, even though the furnace was purged with nitrogen. Next, a titanium plate was embedded in activated carbon powder and was treated under the same heating conditions. An XRD pattern of the surface, which was black in color, is shown in Fig. 3(b). Small diffraction peaks around $40^{\circ}$ were identified as $\alpha$-titanium and $\mathrm{Ti}_{2} \mathrm{~N}$, whereas the intense ones were roughly consistent with those for $\mathrm{TiC}$ and TiN. According to Matsuura et al., ${ }^{8)}$ the large peaks indicate the formation of $\mathrm{Ti}(\mathrm{C}, \mathrm{N})$. Figures 4(a) and 4(b) show optical and SEM micrographs of the cross section of the titanium plate heat-treated with the activated carbon powder, respectively. A reaction layer with a thickness of approximately $5 \mu \mathrm{m}$ was observed on the titanium surface. On the basis of XRD patterns and compositional analysis, this layer was determined to be $\operatorname{Ti}(\mathrm{C}, \mathrm{N})$. Thus, we concluded that the utilization of the activated carbon powder helped to prevent oxidation and to form the $\operatorname{Ti}(\mathrm{C}, \mathrm{N})$ layer.

A titanium plate heat-treated at $1273 \mathrm{~K}$ for $3.6 \mathrm{ks}$ in a nitrogen flow using mixtures of the steel and activated carbon powders became golden brown in color. Figure 3(c) shows an XRD pattern of the titanium surface after heat treatment using a 10:90 (v/v) mixture of steel and activated carbon powders. Addition of the steel powder caused the diffraction peaks for $\alpha$-titanium and $\mathrm{Ti}_{2} \mathrm{~N}$ to become smaller, whereas those for $\mathrm{Ti}(\mathrm{C}, \mathrm{N})$ were more resolved. The XRD pattern was independent of the amount of steel powder in the powder mixture. Figures 4(c) and 4(d) show SEM micrographs of the cross section of titanium plates heat-treated in powder mixtures. The volume fractions of the steel powder used in Figs. 4(c) and 4(d) were 10 and 40 vol\%, respectively. In comparison with Fig. $4(\mathrm{~b})$, the $\operatorname{Ti}(\mathrm{C}, \mathrm{N})$ layers formed on the titanium surface were remarkably thick. Therefore, the steel powder may contribute to enhancing the activities of carbon and nitrogen during heat treatment. In addition, a solid solution region, which was formed by the diffusion of carbon and nitrogen into titanium, was found along the $\operatorname{Ti}(\mathrm{C}, \mathrm{N})$ layer. It should be noted that there were defects, such as voids, in the $\operatorname{Ti}(\mathrm{C}, \mathrm{N})$ layers. Since the defects in the $\operatorname{Ti}(\mathrm{C}, \mathrm{N})$ layers were observed in all cases, as shown in Fig. 4, the occurrence of defects is related to the formation of the $\mathrm{Ti}(\mathrm{C}, \mathrm{N})$ layers. Furthermore, needle-shaped products formed in the titanium plates heat-treated in the powder. The microstructure corresponding to such products can be seen even in Fig. 4(a). They appeared after etching, and there were no obvious differences in the composition of the titanium matrix and the product. The defects in the $\operatorname{Ti}(\mathrm{C}, \mathrm{N})$ layers and the needle-shape products are still under investigation.

The authors have reported that heat treatment in mixtures of steel and activated carbon powders results in the generation of carbon monoxide (CO) as the temperature is increased. ${ }^{9}$ ) This is probably due to chemical reactions between the carbon in the steel and activated carbon powders and residual oxygen in the furnace. $\mathrm{CO}$ generation was also confirmed in the present study. Since the free energy of formation for $\mathrm{TiO}_{2}$, which is predicted to exist on the titanium surface as an oxide film, is lower than that for $\left.\mathrm{CO},{ }^{10}\right)$ it is difficult to reduce the oxide film by CO directly. Since $\mathrm{CO}$ is exhausted with the nitrogen flow from the furnace, oxygen in the furnace should also be expelled. Accordingly, it is thought that a decrease in the oxygen partial pressure contributes to the decomposition of the oxide film on the titanium surface, making it easy for carbon and nitrogen to diffuse into the titanium.

Vickers hardness tests were carried out to reveal the effects of the powder mixture on the surface hardness of the heattreated titanium plates. Figure 5 shows the relationship between the ratio of the steel powder in the powder mixture and the surface hardness of the titanium plates heat-treated at 


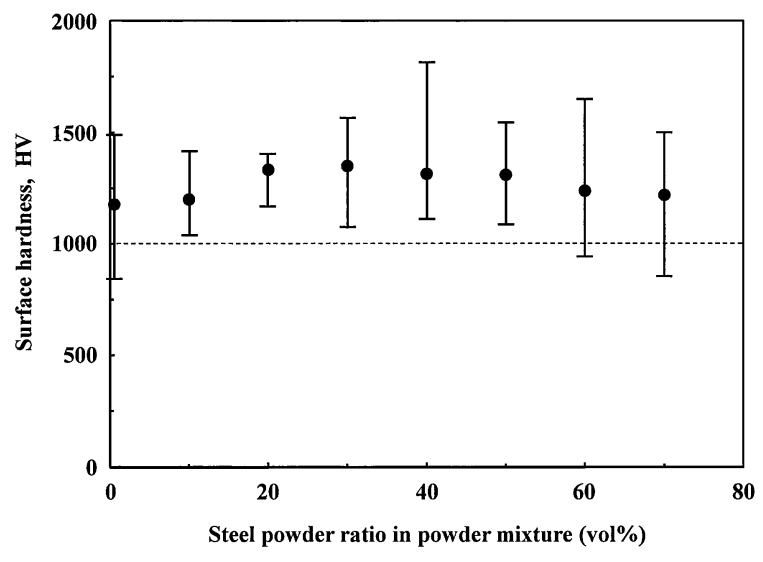

Fig. 5 Effect of steel powder ratio in the powder mixture on the surface hardness of a titanium plate heat-treated at $1273 \mathrm{~K}$ for $3.6 \mathrm{ks}$ in a nitrogen flow. The powder mixtures were composed of steel and activated carbon powders.

$1273 \mathrm{~K}$ for $3.6 \mathrm{ks}$ in a nitrogen flow. The measurements were conducted at least seven times for each specimen. In each case, the surface hardness was more than $\mathrm{HV}=1000$ and was much higher than that of the untreated titanium plate, which had a hardness of HV $=190$. The addition of the steel powder to the activated carbon powder resulted in a higher surface hardness. Although there was no significant change in Fig. 5, the titanium plate heat-treated in a $40: 60(\mathrm{v} / \mathrm{v})$ mixture of the steel and activated carbon powders had a relatively high hardness. Therefore, it was used in subsequent experiments.

\subsection{Effects of the heating temperature}

To examine the relationship between the heating temperature and the formation of the $\operatorname{Ti}(\mathrm{C}, \mathrm{N})$ layer, titanium plates were heat-treated at various temperatures in the $40: 60(\mathrm{v} / \mathrm{v})$ steel/activated carbon mixture. XRD patterns of the titanium plates heat-treated at 873,1073 and $1273 \mathrm{~K}$ are shown in Figs. 6(a)-6(c), respectively. The plates were held at each temperature for $3.6 \mathrm{ks}$ in a nitrogen flow. At $873 \mathrm{~K}$, no reaction products were detected, and all of the diffraction peaks corresponded to $\alpha$-titanium. After heat treatment at $1073 \mathrm{~K}$, the peaks for not only $\alpha$-titanium but also $\beta$-titanium and $\operatorname{Ti}(\mathrm{C}, \mathrm{N})$ were observed. The formation of $\beta$-titanium was attributed to the diffusion of iron, which is a $\beta$-stabilizer for titanium. The diffraction peaks for $\beta$-titanium and $\operatorname{Ti}(\mathrm{C}, \mathrm{N})$ were too small, and they could not be identified in SEM images. As the heating temperature increased, the $\mathrm{Ti}(\mathrm{C}, \mathrm{N})$ peaks became more intense. The titanium plate heat-treated at $1273 \mathrm{~K}$ was coated with a $\mathrm{Ti}(\mathrm{C}, \mathrm{N})$ layer, as shown in Fig. 4(d), and this microstructural feature was reflected in the XRD pattern in Fig. 6(c).

Due to the $\operatorname{Ti}(\mathrm{C}, \mathrm{N})$ layer, the surface hardness of the titanium plate heat-treated at $1373 \mathrm{~K}$ in the powder mixture was similar to that at $1273 \mathrm{~K}$. Therefore, specimens with a $\mathrm{Ti}(\mathrm{C}, \mathrm{N})$ layer had the highest hardness values, independent of the heating temperature. In other words, a heating temperature of $>1273 \mathrm{~K}$ was necessary to form a uniform $\mathrm{Ti}(\mathrm{C}, \mathrm{N})$ layer on the titanium surface. However, the heating temperature must be considered because the powder mixture, which is composed of steel and activated carbon powders,

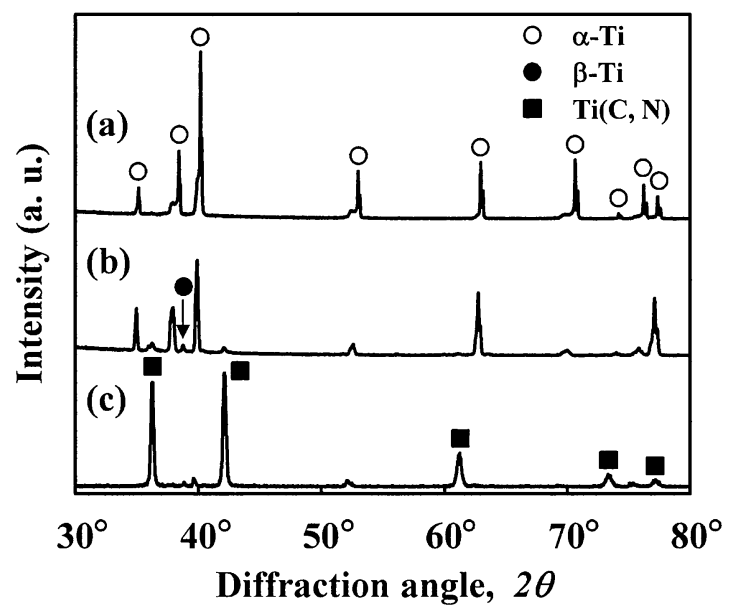

Fig. 6 XRD patterns of the surface of a titanium plate heat-treated at (a) 873 , (b) 1073 and (c) $1273 \mathrm{~K}$ for $3.6 \mathrm{ks}$ in a nitrogen flow using 40:60 $(\mathrm{v} / \mathrm{v})$ mixture of steel and activated carbon powders.

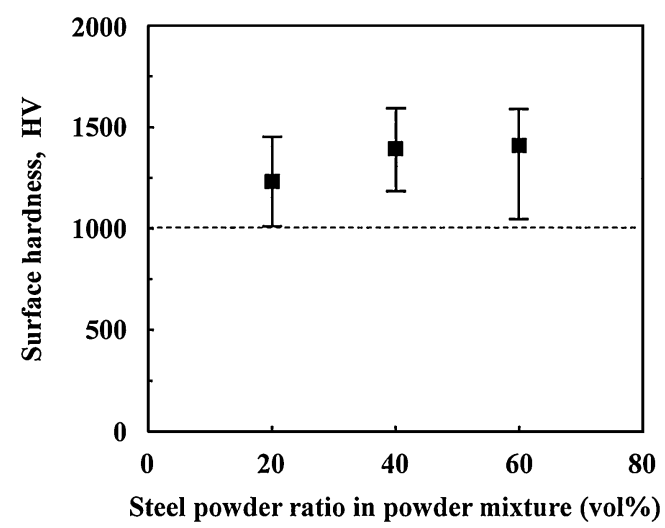

Fig. 7 Surface hardness of a titanium plate heat-treated at $1273 \mathrm{~K}$ for $3.6 \mathrm{ks}$ in a nitrogen flow in mixtures of steel and graphite powders.

will melt at temperatures above the eutectic point (1426 K) in the $\mathrm{Fe}-\mathrm{C}$ binary phase diagram.

\subsection{Use of graphite and alumina powders}

Instead of activated carbon, graphite was mixed with steel powder, and the effects of the carbon powder on the formation of the $\operatorname{Ti}(\mathrm{C}, \mathrm{N})$ layer were examined. Figure 7 shows the surface hardness values of titanium plates heattreated at $1273 \mathrm{~K}$ for $3.6 \mathrm{ks}$ in a nitrogen flow using mixtures with different ratios of steel and graphite powders. In comparison with Fig. 5, it appears that there is little change in the average values and distributions of the surface hardness values. Since activated carbon has small pores and a high degree of microporosity, there is a risk of substances adsorbed in the pores, like water molecules, exerting some influence on the formation of the $\operatorname{Ti}(\mathrm{C}, \mathrm{N})$ layer. Therefore, graphite is thought to be better suited as a carbon powder.

Subsequently, alumina powder was added to the steel/ graphite mixtures to make it easier to take the titanium plate out of the powder mixture after heat treatment. Figure 8 shows an SEM micrograph and compositional profiles of titanium, carbon and nitrogen near the titanium surface after heat treatment at $1273 \mathrm{~K}$ for $3.6 \mathrm{ks}$ in a nitrogen flow using the powder mixture. The ratio of steel, graphite and alumina in the powder mixtures was $40: 60: 30(\mathrm{v} / \mathrm{v} / \mathrm{v})$. After heat 

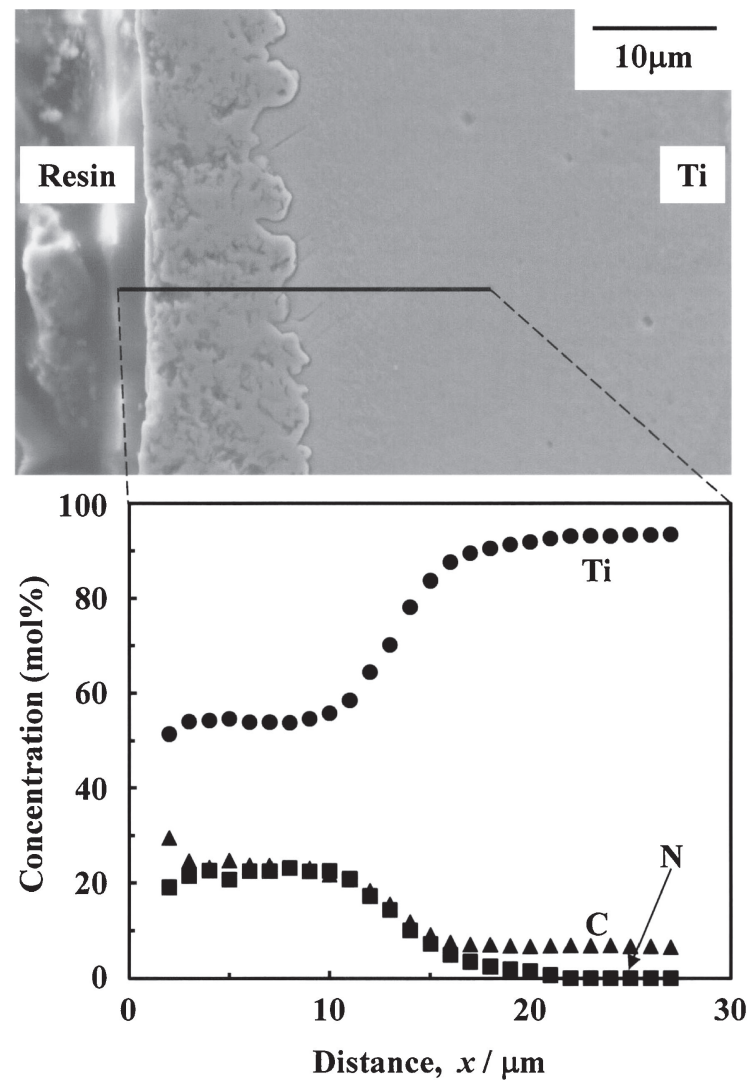

Fig. 8 SEM micrograph and compositional profiles of titanium, carbon and nitrogen in the vicinity of the surface of a titanium plate heat-treated at $1273 \mathrm{~K}$ for $3.6 \mathrm{ks}$ in a nitrogen flow using a $40: 60: 30(\mathrm{v} / \mathrm{v} / \mathrm{v})$ mixture of steel, graphite and alumina powders.

treatment, the titanium plate was easily taken out of the powder mixture and had a $\operatorname{Ti}(\mathrm{C}, \mathrm{N})$ layer on its surface. Considering the influence of etching conducted before observing the microstructures, the microstructure was similar to that in Fig. 4. This indicates that the use of graphite and alumina does not have a negative effect on the layer formation on the titanium surface. In the $\operatorname{Ti}(\mathrm{C}, \mathrm{N})$ layer, the carbon content was similar to the nitrogen content, whereas the titanium content was slightly higher than the stoichiometric composition of $\mathrm{TiC}$ and $\mathrm{TiN}$. According to the Ti-C and $\mathrm{Ti}-\mathrm{N}$ binary phase diagrams, ${ }^{11,12)} \mathrm{TiC}$ and $\mathrm{TiN}$ have large composition ranges toward the titanium-rich side. This may be part of the reason for the formation of the titanium-rich $\mathrm{Ti}(\mathrm{C}, \mathrm{N})$ layer. On the other hand, oxygen was scarcely detected in the compositional analysis.

The diffusion distances of carbon and nitrogen into $\alpha$ titanium and $\beta$-titanium were evaluated by using $(2 D t)^{1 / 2}$, where $D$ and $t$ are the diffusion coefficient $\left(\mathrm{m}^{2} / \mathrm{s}\right)$ and the time (s), respectively. When $t$ was $3600 \mathrm{~s}$, the diffusion distance of nitrogen into $\alpha$-titanium was estimated to be approximately $12 \mu \mathrm{m}$ at $1273 \mathrm{~K}^{13)}$ This value is consistent with the compositional profile of nitrogen in Fig. 8. This also suggests that a phase transformation from $\beta$-titanium to $\alpha$ titanium may take place in the subsurface region at $1273 \mathrm{~K}$ due to the diffusion of carbon and nitrogen, which are known to be $\alpha$-stabilizers for titanium.

The surface morphological images of the specimen in Fig. 8 are shown in Fig. 9. It seems that the Ti(C, N) layer forms along the remaining traces of the mechanical grinding
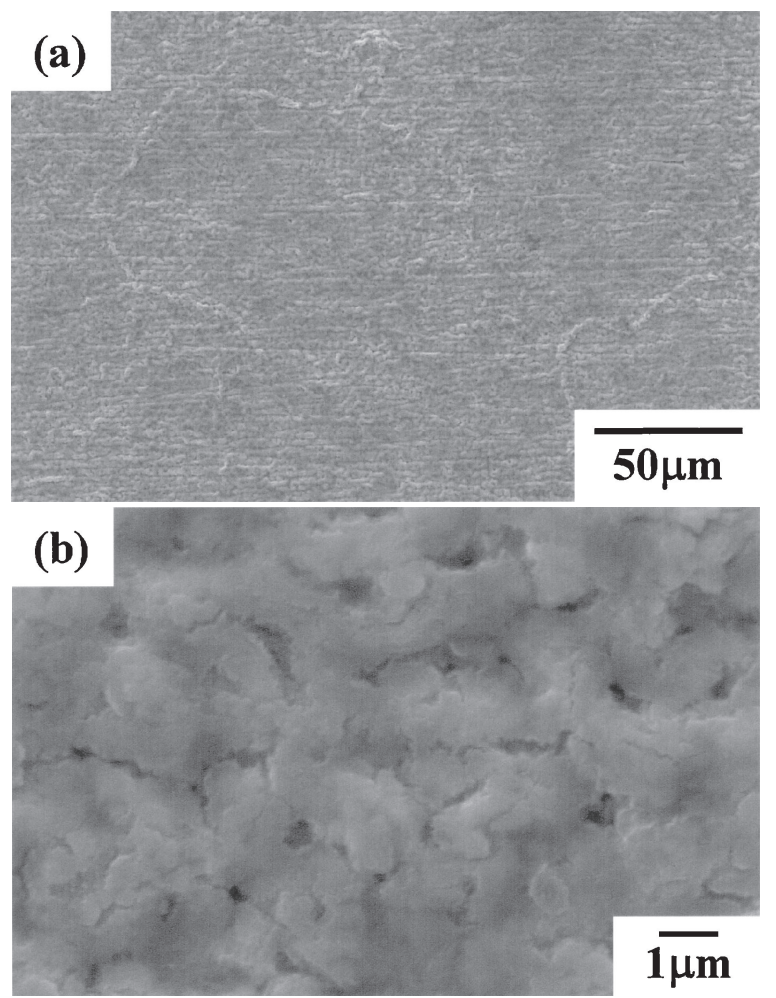

Fig. 9 (a) SEM micrograph of the surface of a titanium plate heat-treated at $1273 \mathrm{~K}$ for $3.6 \mathrm{ks}$ in a nitrogen flow using a $40: 60: 30(\mathrm{v} / \mathrm{v} / \mathrm{v})$ mixture of steel, graphite and alumina powders. (b) Enlarged SEM micrograph of the surface in (a).

before heat treatment. Although minute irregularities and several voids were observed on the surface, the entire surface of the titanium plate was covered with a $\operatorname{Ti}(\mathrm{C}, \mathrm{N})$ layer. The mechanical and chemical properties of titanium with a $\operatorname{Ti}(\mathrm{C}, \mathrm{N})$ layer are currently being studied. However, the $\mathrm{Ti}(\mathrm{C}, \mathrm{N})$ layer obtained in the present study is similar to that reported by Matsuura et $a l .{ }^{8)}$ in many respects. Therefore, it should have excellent wear and corrosion resistance.

\section{Conclusions}

Titanium plates were embedded in mixtures of steel and activated carbon powders and then heated in the temperature range of $773-1373 \mathrm{~K}$ for $3.6 \mathrm{ks}$ in a nitrogen flow. The main results were as follows.

(1) $\operatorname{Ti}(\mathrm{C}, \mathrm{N})$ layers with thicknesses of approximately $10 \mu \mathrm{m}$ formed on the titanium surfaces when the plates were heat-treated at $1273 \mathrm{~K}$ for $3.6 \mathrm{ks}$ using mixtures of steel and activated carbon powders. The surface hardness was more than $\mathrm{HV}=1000$ regardless of the steel powder ratio in the mixtures. The $\operatorname{Ti}(\mathrm{C}, \mathrm{N})$ layers were thicker and harder when mixtures of steel and activated carbon powders were used, compared with when only the activated carbon powder was used.

(2) $\mathrm{CO}$ was detected in the gas exhausted from the furnace during heat treatment. As oxygen in the furnace reacts with carbon in the steel and activated carbon powders to form $\mathrm{CO}$, the oxygen partial pressure should be low around the titanium plate. Therefore, it is thought that the decomposition of the oxide film on the titanium surface is promoted, making it easier for carbon and nitrogen to diffuse into the titanium. 
(3) From XRD results, $\mathrm{Ti}(\mathrm{C}, \mathrm{N})$ began to form on the titanium plate heat-treated at $1073 \mathrm{~K}$ in a $40: 60(\mathrm{v} / \mathrm{v})$ mixture of steel and activated carbon powders. At $1273 \mathrm{~K}$, the titanium plate was coated with a $\mathrm{Ti}(\mathrm{C}, \mathrm{N})$ layer and became golden brown in color.

(4) Graphite was used instead of activated carbon, and alumina was added to the mixture of steel and graphite powders to reliably prevent the powder mixture from sintering. It was found that the addition of graphite and alumina powders did not have a negative impact on the formation of a $\operatorname{Ti}(\mathrm{C}, \mathrm{N})$ layer on the titanium surface.

\section{Acknowledgements}

The authors would like to express their appreciation to Dr. H. Fujii and Mr. K. Mori of Nippon Steel \& Sumitomo Metal Corporation for their helpful comments in the experiments. We greatly appreciate support from the Adaptable and Seamless Technology Transfer Program through Targetdriven R\&D, JST and the JSPS Grant-in-Aid for Scientific Research (C) (No. 24560887).

\section{REFERENCES}

1) A. Takamura: J. Jpn. Inst. Metals 24 (1960) 565-569.

2) T. Bell, H. W. Bergmann, J. Lanagan, P. H. Morton and A. M. Staines: Surf. Eng. 2 (1986) 133-143.

3) E. Roliński: Mater. Sci. Eng. A 108 (1989) 37-44.

4) N. Kanayama, Y. Horie and T. Tanabe: J. Surf. Finish. Soc. Jpn. 44 (1993) 683-686.

5) A. Chiba, M. Nishida, Y. Morizono and K. Imamura: J. Phase Equilibria 16 (1995) 411-415.

6) Y. Morizono, M. Nishida, A. Chiba, T. Yamamuro, Y. Kanamori and T. Terai: Mater. Trans. 45 (2004) 527-531.

7) Y. Morizono, T. Yamamuro and M. Nishida: Mater. Trans. 48 (2007) 1476-1482.

8) K. Matsuura and M. Kudoh: Acta Mater. 50 (2002) 2693-2700.

9) Y. Morizono, S. Tsurekawa and T. Yamamuro: Tetsu-to-Hagane 98 (2012) 476-481.

10) Metals Data Book, ed. by Jpn. Inst. Metals, (Maruzen Co., Ltd., 1993) p. 96.

11) J. L. Murray: Phase Diagrams of Binary Titanium Alloys, (ASM International, 1987) pp. 47-51.

12) J. L. Murray: Phase Diagrams of Binary Titanium Alloys, (ASM International, 1987) pp. 176-186.

13) Metals Data Book, ed. by Jpn. Inst. Metals, (Maruzen Co., Ltd., 1993) pp. 20-25. 